\title{
A Vocação Política das Ciências Sociais
}

\author{
Octávio Ianni
}

\section{Ciência e política}

A maioria dos cientistas sociais reconhece que a pesquisa científica, no campo das ciências sociais, possui implicações políticas. Eles reconhecem que, direta e indiretamente, a pesquisa feita pelo economista, sociólogo, politicólogo, antropólogo, psicólogo e historiador tem conotação política. Também os trabalhos do psicólogo e historiador não escapam a essa conotação. É claro que as implicações políticas são mais evidentes quando se trata da pesquisa sobre um problema do presente, ou situação na qual os homens do presente estão empenhados. Mas também quando a pesquisa tem como objeto uma situação passada ela pode ter implicações políticas. Quando se diz que cada "geração" refaz a história do seu país, diz-se inclusive que cada regime político, ou governo, reinterpreta o passado à luz da sua imagem do presente. Às vezes procura-se glorificar o passado, ou uma parte dele. Outras vezes procura-se mostrar que o presente é totalmente novo, apresentando uma ruptura revolucionária com o passado. $\mathrm{E}$ assim por diante.

A própria escolha do tema da pesquisa frequentemente envolve uma opção política. Essa opção pode ser aberta ou velada. Inclusive pode ocorrer - como ocorre frequentemente - que o cientista não tenha ciência dessa implicação. Aliás, muitas vezes o cientista social nega qualquer relação do seu trabalho (ensino, pesquisa, tema, hipótese, problema etc.) com qualquer valor político, ou valor extracientífico. Independentemente da importância teórica ou metodológica da pesquisa, muitas vezes ela é gerada, desde o princípio, numa atmosfera política. Em certos casos os beneficiários imediatos ou mediatos são os donos do poder político-econômico. Em outros os interesses em causa são os que se acham fora do poder, ou lutam para conquistar o poder. A pesquisa científica pode estar inspirada seja pela conveniência de preservar dado status quo político-econômico, seja pelo interesse em modificá-lo. Com frequência as hipóteses dos cientistas sociais estão empapadas nos interesses políticos dos grupos e classes sociais, ou dos partidos, empresas e governos. Ocorre que a ciência social é uma técnica de poder.

No que diz respeito ao presente, a implicação política da pesquisa começa pela relação que ela estabelece entre o pesquisador e o pesquisado. Quando se trata de pesquisa de campo, na qual o pesquisador entra numa relação face-a-face com o membro do grupo ou classe 
que se quer conhecer, quase sempre ocorre alguma modificação no pesquisado. Ao realizar uma entrevista, aplicar um questionário, pedir um depoimento, ou obter uma história de vida, o pesquisador põe diante do informante questões e problemas que podem suscitar mudanças no seu modo de ver e avaliar as coisas, as gentes e as suas relações. $\mathrm{E}$ pode mesmo alterar, mais ou menos, o seu modo de comportar-se diante de si, dos membros do seu grupo religioso, na fábrica, escritório, fazenda, sítio, sindicato, partido etc. Dependendo da problemática da pesquisa, da forma pela qual ela é realizada, da situação sócio-econômica do informante, da sua visão política e do seu horizonte cultural, a pesquisa social pode influenciar ou modificar o modo pelo qual ele - como membro de dado grupo ou classe pensa e age. Se a pesquisa lida com o universo de valores, ideais, relações e dilemas de dada pessoa, família, grupo social ou classe social, ela certamente influencia o modo pelo qual o pesquisado compreende e reage aos próprios problemas materiais, intelectuais, políticos, religiosos, morais, econômicos ou outros. A pesquisa pode propiciar a conscientização de uma condição social de vida. Mas não é certo que essa conscientização seja aquela que corresponde aos interesses mais fundamentais do "objeto" da pesquisa. Não é certo que o relacionamento do pesquisador com o pesquisado é sempre positivo, ou favorável a este. Algumas vezes pode ser neutro o resultado da situação social de pesquisa; outras, pode ser prejudicial ao pesquisado. Aliás, são frequentes os casos em que o próprio pesquisador é afetado pela experiência da pesquisa; como cientista e como pessoa.

Independentemente dos usos extracientíficos do conhecimento obtido no processo da pesquisa, é inegável que o próprio ato de pesquisar afeta, modifica ou subverte os modos de pensar e agir do operário, funcionário, empregado, caboclo, colono, peão, bóia-fria, migrante, imigrante, criança, mulher, adulto, paciente, negro, mulato, mestiço, índio que aparece no projeto do pesquisador como objeto de pesquisa ou informante. Assim, o ato de pesquisar, a situação de entrevista, aplicação de questionário, obtenção de depoimento ou história de vida é, frequentemente, um ato de modificar o outro.

É claro que o ato de modificar o outro é um ato essencialmente político. Afinal de contas as pessoas não vivem no vácuo, mas trabalham nos quadros das relações de produção e estruturas de poder econômico e político que correspondem - ou não correspondem aos seus interesses de classe. Ao modificar o outro, a pesquisa ajuda ou induz o pesquisado a reelaborar os quadros de referência sobre as suas relações e as suas condições de vida, em termos práticos e ideológicos. Quando inserido no processo de pesquisa, o pesquisado pode elaborar novos quadros de consciência sobre a própria situação social, isto é, sobre a sua situação político-econômica. Muitas vezes, a pesquisa é pensada, desde o princípio, com um instrumento destinado a produzir informações e conhecimentos para "ajudar" ou "favorecer" o favelado, o marginalizado, o desempregado, o operário, o caboclo, o negro, o índio a outros. Nesses casos, ela já se inicia como uma ação organizada segundo interesses, motivos, razões políticas e econômicas, que se expressam como "humanitários", "morais" ou de outra forma, e se impõem ao pesquisado, como pessoa, família, grupo social, classe social. Nesses casos, a pesquisa desempenha, direta e explicitamente, a função de uma técnica de "mudança social provocada", "reversão de expectativas", "modernização", ou simplesmente manipulação e dominação.

Mas o problema não termina nesse passo. A produção científica, nas ciên- 
cias sociais, é um processo complexo, que se desdobra além do que aparece habitualmente nos termos e na prática do projeto da pesquisa.

$\mathrm{O}$ produto do trabalho científico, nas ciências sociais, muitas vezes tende a incorporar-se ao objeto do conhecimento. Isto significa que o conhecimento produzido passa a ser parte da realidade social, como pensamento e prática. Além da modificação eventual que o processo da pesquisa pode provocar no modo de pensar e agir do pesquisado, o conhecimento científico pode passar a compor o mundo cultural e material dos grupos e classes sociais, ou da sociedade como um todo. No século XX, os pensamentos de Marx, Weber, Lenin, Freud e Keynes, para mencionar apenas alguns cientistas sociais, passaram a fazer parte da cultura e prática de governantes, partidos, associações, empresas, grupos, igrejas e classes sociais. Não quero dizer que sempre são encarados da mesma forma. Ao contrário, são utilizados, desenvolvidos, combatidos, negados, deteriorados. Inclusive têm sido e continuam a ser moda, formas de dizer, artifícios de discurso, retórica de salão. Mas são pensamentos que permeiam os trabalhos e os dias das gentes, em países dominantes, dependentes e coloniais. As sociedades do século XX, como sociedades capitalistas e socialistas, não podem ser compreendidas se a análise não passar pela produção intelectual desses autores, seus seguidores, epígonos e detratores. Sob muitas formas - científicas, técnicas e ideológicas essa produção intelectual está presente nas decisões, políticas e pesquisas de governos, empresas, partidos, universidades, instituições de pesquisa e outras esferas de poder e reprodução material e cultural.

Como vemos, da mesma forma que operam no processo de "desencantamento do mundo", as ciências sociais também provocam o "desencantamento" do cientista social. Por suas implicações extra-científicas - tanto quanto por suas implicações científicas - as ciências sociais desencantam o mundo social e o cientista social. Provavelmente o mais grave desafio que toda ciência social põe diante do cientista é a descoberta dos conteúdos e implicações políticos da produção científica. Quando o cientista descobre esse fato - ou compreende todas as suas conotações tanto a ciência social como o próprio cientista são despojados da magia que cerca as coisas do espírito, a atividade intelectual. Ele toma consciência de que é um produtor, adaptador ou imitador de fórmulas científicas, técnicas, ideológicas que servem à reprodução das relações e estruturas político-econômicas. Esse é, a meu ver, o segredo do desencantamento do cientista social provocado pela própria ciência social. Ou o cientista social reconhece e procura controlar as condições e implicações políticas da sua produção intelectual, ou ele se transforma num instrumento - ativo, dócil, resignado - dos interesses políticos, econômicos, militares, religiosos e outros, alheios ou mesmo adversos ao seu próprio trabalho. Penso que o cientista social não pode menosprezar nem as condições nem os usos políticos do seu trabalho. Ao tomar consciência dos conteúdos e implicações extracientíficos do seu trabalho - em todas as fases do processo de produção intelectual o cientista social precisa lutar para que os seus objetivos científicos e políticos não sejam desbaratados nem pelas estruturas burocráticas, ou indústrias de pesquisa, nem pela ilusão da ciência pura.

\section{Técnica de poder}

No campo das ciências sociais, a pesquisa científica não é apenas um momento no processo de produção intelectual. Ela é também uma técnica de poder. Umas vezes, ela é parte das rela- 
ções e estruturas de dominação. Outras, é parte da luta para mudar, romper ou refazer relações e estruturas de dominação. Esse duplo caráter das ciências sociais aparece em toda a sua história.

Tal vez corresponda al destino de las ciencias sociales no sólo el que deban reflejar las formas dominantes de la organización social de su época sino también - como lo han hecho desde que se desprendieron del pensamiento social y político de la Ilustración que deban convertirse en medios importantes para la expresión de las contracorrientes radicales y de la conciencia crítica que estas mismas formas de organización ha originado. Esta relación dialéctica entre las ciencias sociales y la sociedad logra penetrar en los papeles conflictivos y frecuentemente ambiguos que los científicos sociales, como indivíduos, se ven forzados a desempeñar en la sociedad moderna (1).

No que diz respeito ao seu caráter de técnica de dominação, a pesquisa científica tem sido amplamente utilizada pelos governantes, empresas, partidos e igrejas para conhecer os grupos e classes sociais subordinados, dentro e fora do mesmo país. Isso tem ocorrido em vários setores das relações e estruturas sociais, desde a sociologia industrial até à antropologia dos povos colonizados e dependentes. Vejamos o que escreveram Loren Baritz, Robert S. Lynd e Frederick Taylor sobre a pesquisa científica na

(1) Rodolfo Stavenhagen, Sociologia y Subdesarrollo, Editorial Nuestro Tiempo, México, 1972, p. 207. Citação do cap. intitulado "Como descolonizar las ciencias sociales?", pp. 207-234. Consultar também: Florestan Fernandes, $A$ Sociologia numa Era de Revolução Social, Companhia Editora Nacional, São Paulo, 1963, Octavio Ianni, Sociologia da Sociologia Latino-Americana, Editora Civilização Brasileira, Rio de Janeiro, 1971. fábrica, no quartel e na guerra, sempre para controlar, dominar ou modificar assalariados, subalternos e populações que lutam por emancipar-se das condições adversas em que vivem.

Baritz: By the middle of the twentieth century, industrial social science had become one of the most pregnant of the many devices available to America's managers in their struggle with costs and labor, government and the consuming public (2).

As part of the bureaucratization of virtually every aspect of American life, most industrial social scientists labored in industry as technicians, not as scientists. Not professional concerned with problems outside the delimited sphere which management had assigned to them, not daring to cross channels of communication and authority, they were hemmed in by the very organization charts which they had helped to contrive. And the usual industrial social scientist, because he accepted the norms of the elite dominant in his society, was prevented from functioning critically, was compelled by his own ideology an the power of America's managers to supply the techniques helpful to managerial goals (3).

Lynd. These volumes (The American Soldier) depict science being used with great skill to sort out and to control men for purposes not of their own willing. It is a significant measure of the impotence of liberal democracy that it must increasingly use its social sciences not directly on democracy's own problems, but tangentially and indirectly; it must pick up

(2) Loren Baritz, The Servants of Power (A History of the use of Social Science in American Industry), John Wiley and Sons, New York, 1965, p. 191.

(3) Loren Baritz, op. cit., p. 194. 
the crumbs from private business research on such problems as how to gauge audience reaction so as to put together synthetic radio programs and movies, or, as in the present case, from Army research on how to turn frightened draftees into tough soldiers who will fight a war whose purposes they do not understand. With such socially extraneous purposes controlling the use of social science, each advance in its use tends to make it an instrument of mass control, and thereby a further threat to democracy (4).

Taylor: The U.S. effort for peace and freedom in Southeast Asia is getting an assist from a strange source: The psychologists, sociologists and other such behavioral scientists.

In various U.S. financed research projects, the Vietnamese, the Thait, their lives and habitat are being scrutinized much as Americans themselves have long been analyzed. The studies sometimes are resulting in changes in the lives of the Asians; occasionally, they are resulting in changes in the war. ...

The aim of Camelct (1965) was to isolate the factors making for revolutionary change in the developing nations and to identity the way the Communists capitalize on these

(4) Robert S. Lynd, "The Science of Inhuman Relations", The New Republic, 27 August 1949. Citado por C. Wright Mills, The Sociological Imagination, Oxford University Press, New York, 1959, p. 115. Lynd se refere à seguinte pesquisa: Samuel A. Stouffer, E. A. Suchman, L. C. De Vinney, S.A. Star, R. M. Williams Jr., A. A. Lumsdaine, M. H. Lumsdaine, M. B. Smith, I. L. Janis and L. S. Cottrell Jr., The American Soldier, vol. I (Adjustment during Army life) and vol. II (Combat and its aftermath), Princeton University Pres, Princeton, 1949. factors to take over a country or foment a Vietnam-type .war. Chile was the land chosen for the study ${ }^{(5)}$.

A forma pela qual ocorreu e continua a ocorrer a burocratização e a industrialização da produção científica nas ciências sociais tende a transformar a pesquisa principalmente numa técnica política. Ela pode servir aos fins dos governantes, militares, empresários e outros, tanto para acelerar a produção de capital como para aperfeiçoar o domínio sobre grupos, classes e nações. Nessa perspectiva, o cientista aparece como um intelectual que produz conhecimento (em forma científica, técnica, prática ou ideológica) que possibilita "aperfeiçoar" as relações e estruturas de dominação política e apropriação econômica vigentes em dado país, época, conjuntura, regime político etc. Devido às condições de racionalização estabelecidas pela reprodução capitalista, o cientista, técnico, assessor e outras classificações passam a ser as novas categorias de funcionários indispensáveis à continuidade do processo de reprodução das relações e estruturas capitalistas, nos países dominantes, dependentes e coloniais. Em reflexões sobre os intelectuais e a organização da cultura, Gramsci mostra como os intelectuais são inseridos nas estruturas de poder.

Os intelectuais são os "comissários" do grupo dominante para o exercício das funções subalternas da hegemonia social e do governo político, isto é: 1) do consenso "espontâneo" dado pelas grandes massas da população à orientação impressa pelo grupo fundamental dominante à vida social, consenso que nasce "historicamente" do prestígio (e, portanto da confiança que o grupo dominante obtém, por

(5) Frederick Taylor, "Know Your Ally", The Wall Street Journal, New York, June 1, 1967, p. 1. 
causa da sua posição e da sua função no mundo da produção; 2)do aparato de coerção estatal que assegura "legalmente" a disciplina dos grupos que não consentem, nem ativa nem passivamente, mas que é constituído para toda a sociedade, na previsão dos momentos de crise no comando e na direção, nos quais fracassa a consenso espontâneo (6).

Sob vários aspectos, a ciência é uma técnica de dominar, controlar ou modificar o outro. Esse outro pode ser operário, camponês, lavrador, empregado, adulto, criança, negro, índio; um. grupo social, classe social, nação. Nesse sentido, também, é que a ciência social faz parte do processo de "desencantamento do mundo", que fascina e incomoda a todo cientista social, antes e depois de Max Weber.

Weber não quis aceitar - em 1918, na Universidade de Munich, quando falou sobre a ciência como vocação - que a política que invadia as aulas e as palavras dos professores de sociologia, política, economia, história e outras disciplinas não era um elemento totalmente espúrio, mas apenas uma nova manifestação dos conteúdos e implicações das ciências sociais. Ele queria a ciência livre de preocupações e valores extraordinários, feita em estado de isenção. Lamentava a invasão das salas de aula e do trabalho científico por "seitas de fanáticos" e "profetas", que subvertiam a ética acadêmica e científica liberal que morria exatamente nessa época. Em 1918, a Alemanha havia sido derrotada na guerra, o conflito entre nações imperialistas havia lançado soldados, operários e camponeses numa situação desesperadora, a luta de classes estava nas ruas, o poder

(6) Antonio Gramsci, Os Intelectuais e a Organização da Cultura, trad. de Carlos Nelson Coutinho, Editora Civilização Brasileira, Rio de Janeiro, 1968, p. 11. soviético já se havia instalado na Russia e o fascismo começava a ser gestado. Mas Weber defendia a independência e a isenção do trabalho científico, no ensino e pesquisa. Queria preservar uma racionalidade ideal nas próprias ciências sociais. Depois de descobrir que as ciências sociais eram parte do processo de racionalização crescente das ações, relações e organizações sociais, Weber julgava indispensável afastar dos ambientes científicos as "revelações", a "graça" e as "profecias". Queria que as ciências sociais fossem livradas dos encantamentos mágicos, isto é, políticos, para que elas pudessem melhor servir à sua vocação de desencantar o mundo.

The increasing intellectualization and rationalization do not, therefore, indicate an increased and general knowledge of the conditions one lives. It means something else, namely, the knowledge or belief that if one but wished one could learn it at any time. Hence, it means that principally there are no myisterious incalculable forces that come into play, but rather that one can, in principle, master all things by calculation. This means that the world is disenchanted (7).

Science today is a "vocation" organized in special disciplines in the service of self-clarification and knowledge of interrelated facts. It is not the gift of grace of seers and prophets dispensing sacred values and revelations, nor does it partake of the contemplation of sages and philosophers about the meaning of the universe ${ }^{(8)}$.

(7) H. H. Gerth and C. Wright Mills (Editors), From Max Weber: Essays in Sociology, Kegan Paul, Trench, Trubner \& Co., London, 1949, p. 139. Esta e as duas citações seguintes foram retiradas do texto de "Science as a Vocation", pp. 129-156.

(8) H. H. Gerth and C. Wright Mills (Editors), op. cit., p. 152. 
The fate of our time is characterized by rationalization and intellectualization and, above all, by the "disenchantment of the world" (9).

Weber parecia resistir heroicamente a uma realidade que se impunha a tudo e todos, inclusive à sua obra. As exigências das relações e estruturas do capitalismo politizavam generalizadamente as relações sociais e os produtos destas relações, inclusive o trabalho científico, na sala de aula e na pesquisa. A própria obra de Weber, construída no mais rigoroso espírito científico, não escapou a essa politização universal das ciências sociais. Em primeiro lugar, uma parte de sua obra foi e continua a ser utilizada, científica e ideologicamente, como uma explicação alternativa à de Marx, quanto às leis e tendências que regem os movimentos históricos do capitalismo. Esse é um debate que transborda das salas de aulas, ensaios e livros, para localizar-se diretamente na luta de classes, nas contradições entre proletariado e burguesia. Em segundo lugar, uma parte da obra de Weber tem frutificado - muitas vezes de forma deteriorada, é certo - na produção científica, técnica e ideológica de cientistas sociais empenhados, cientes ou não, em aprimorar o funcionamento e o rendimento de estruturas capitalistas de dominação política e apropriação econômica.

\section{Indústria da pesquisa}

Para compreender melhor as principais implicações políticas da pesquisa científica, precisamos reconhecer que ela envolve um processo intelectual e organizatório complexo; processo esse que supõe recursos administrativos, tecnológicos e financeiros, além de hierarquias e sub-hierarquias de várias ordens.

(9) Ibidem, p. 155.
Mesmo quando o pesquisador trabalha só - ao longo das várias fases do processo de produção intelectual - mesmo nesse caso o seu trabalho envolve condições extra-intelectuais importantes. Mas é no trabalho de equipe, nas organizações de pesquisa, ou na indústria de pesquisa, que o processo de produção intelectual se torna financeira e organizatoriamente complexo e vultoso. Principalmente nessas condições, a pesquisa supõe um processo intelectual complicado, mesclado com relações e estruturas de cunho extra-científico; relações e estruturas essas que podem ajudar ou prejudicar a produção científica original e independente.

Nas universidades, faculdades, institutos e centros, públicos e privados, a pesquisa social muitas vezes se ajusta a interesses e exigências extra-científicos. Por um lado, devido aos vínculos explícitos ou implícitos que se estabelecem com os financiamentos das pesquisas. $\mathrm{Na}$ maioria dos casos, os financiadores de pesquisas sociais - em países dominantes, dependentes e coloniais - são governos, empresas, partidos, fundações e outras entidades empenhadas em programas direta ou indiretamente relacionados com interesses políticos ou econômicos. Por outro lado, a própria estruturação burocrática das atividades científicas afeta a independência e a criatividade do intelectual. As razões financeiras, as hierarquias de prestígio, a adesão à moda, a conveniência de preservar e ampliar grupos e estruturas, tudo isso interfere na essência do trabalho intelectual. Algumas vezes essa interferência é bastante negativa. A distorção, ou mesmo inversão, do trabalho intelectual tem sido examinada por vários cientistas sociais. Vejamos o que escreveram Barrington Moore Jr., André Gorz e C. Wright Mills. Eles põem os principais aspectos da relação entre a burocratização do trabalho científico, ou do funcionamento da indústria da pes- 
quisa, com os conteúdos e significados políticos das ciências sociais. E põem inclusive o problema do diálogo entre o cientista e a sociedade.

Moore Jr.: At a more detailed level of analysis one may note that many modern social science research projects are very expensive affairs. They require the collaboration of a large number of persons with a variety of skills and training. Often their cost exceeds several hundred thousand dollars. It may be unfair to remark that the results are not always in proportion to the costs. But it is true that the present situation in social science is the exact reverse of what prevailed during the great theoretical discoveries in physics in the nineteenth and early twentieth centuries. Revolutionary advances were made with limited funds and, by modern standards, crude laboratory equipment. Today, in social science at any rate, the effect of large grants is to give to those in control of the allocation of research funds a high strategic position for determining which problems will be investigated and which will not. Under the present situation the need to be a cooperative member of a research team may do more to stultify original and critical thinking than direct economic pressure (10).

Gorz: L'expansion principale des activités de recherche, en effect, porte non pas sur la recherche "indépendante" ou fondamentale, mais sur la recherche directement liée au processus de production (11).

(10) Barrington Moore Jr., Political Power and Social Theory, Harper Torchbooks, New York, 1962, pp. 139-140.

(11) André Gorz, "Techniques, techniciens et lutte des classes", Les Temps Modernes, $n^{\circ}$ 301-302, Paris, 1971, pp. 141-180; citação da p. 147.
Mills: Entre o intelectual e seu público potencial estão as estruturas técnicas, econômicas e sociais que são propriedade de outros, e por esses outros operadas (12).

Os meios de comunicação efetiva estão sendo expropriados ao trabalhador intelectual. A base material de sua iniciativa e de sua liberdade intelectual já não está em suas mãos. Alguns intelectuais sentem tal processo em seu próprio trabalho. Sabem mais do que dizem e estão impotentes e temerosos ${ }^{(13)}$.

A burocratização e a industrialização do trabalho intelectual cria vastas $\mathrm{e}$ complexas estruturas - públicas e privadas - que nem sempre beneficiam a pesquisa científica básica e original. Ao contrário, muitas vezes essas organizações aprisionam o cientista numa trama de fins e meios sobre os quais ele tem escassa ou nenhuma influência. Seja qual for a concepção teórica $\in$ a posição política do cientista, as estruturas da produção intelectual lhe impõem os seus temas, as suas hipóteses, os seus procedimentos, as suas condições materiais, organizatórias, técnicas e científicas de produção intelectual. Essa mudança essencial das condições e significados da pesquisa científica pode ser comprovada inclusive pela crescente importância do capital privado no trabalho intelectual, ou pela crescente associação entre capitais privados e públicos em organizações e programas de pesquisa.

A burocratização e a industrialização do processo de produção científica transforma o cientista social num elemento subalterno, ou prisioneiro, de uma organização complexa, que lhe dita o que e como pesquisar. Em muitos casos, o

(12) C. Wright Mills, Poder e Politica, trad. de Waltensir Dutra, Zahar Editores. Rio de Janeiro, 1965, p. 153.

(13) C. Wright Mills, op. cit., p. 155. 
cientista deixa de ser um intelectual independente, de pesquisar o que julga relevante; é levado a trabalhar com os temas que lhe dita a organização, os temas que são de interesse da organização. De certa forma, ele deixa de ser um intelectual para ser um pesquisador, especialista, técnico, assistente, analista, calculista, programador e outras variações. São tais e tantas as relações e estruturas de intermediação que se inserem na atividade intelectual do cientista, que este nem sempre, ou poucas vezes, consegue decidir sobre o que e como pesquisar. Além disso, é levado a especializar-se numa área delimitada da sua disciplina. Essa especialização pode levá-lo a perder interesse por outros campos do conhecimento, menosprezá-los, ou perder de vista o todo. Toda proposição que lhe sugira uma visão mais global dos fatos, relações, processos e estruturas incomodam o seu compromisso com a objetividade, o rigor da observação, a certeza da quantidade, a operacionalização, a verificabilidade. A burocratização e a especializaçą̃o, por um lado, e as exigências da indústria da pesquisa, por outro, tendem a induzir o cientista social a trabalhar de forma bastante rigorosa sobre problemas secundários ou irrelevantes. Toma-se a precisão metodológica como sucedâneo da precisão teórica. Essa inversão entre técnica e ciência já havia sido notada na década dos anos trinta, por Florian Znaniecki, quando discutiu a importância da indução quantitativa na sociologia. Depois, também Barrington Moor Jr. abordou a questão.

Znaniecki: This influence consists in substituting tabulating technique for intellectual methods, and thus eliminating theoretic thinking from the process of scientific research ${ }^{(14)}$.

(14) Florian Znanieck, The Method of Sociology, Rinehart \& Company, New York, 1934, p. 234.
Moore Jr.: The trouble with this procedure is that it starts with the assumption that the facts of history are separate and discrete units ${ }^{(15)}$.

A verdade é que a crescente burocratização e industrialização do processo de produção intelectual está transformando o significado essencial do trabalho científico. A burocratização das condições de pesquisa nas universidades, faculdades, institutos e centros, públicos e privados, nem sempre tem criado melhores condições de produção intelectual. Devido à divisão social de trabalho científico e à conseqüente especialização do cientista, criaram-se hierarquias e sub-hierarquias que às vezes pouco ou nada têm a haver com as exigências da pesquisa científica propriamente dita. A participação dos cientistas sociais das várias disciplinas — e dentro da mesma disciplina - é hierarquizada segundo critérios funcionais, administrativos, salariais e outros. Essas divisões e subdivisões diversificam e diferenciam os cientistas, especialistas, técnicos, auxiliares de pesquisa, seniors e juniors, ou professores titulares, adjuntos, livre-docentes, assistentes doutores, simples assistentes e auxiliares de ensino, segundo as exigências das relações e estruturas burocráticas, antes do que exigências intelectuais. Conforme sugere André Glucksmann, "esta hierarquia do saber tornou-se uma segunda natureza" do trabalho intelectual ${ }^{(16)}$. Isto é, por sobre a essencia do trabalho intelectual, que exige uma atividade livre, criativa e crí-

(15) Barrington Moore Jr., Political Power and Social Theory, citado, p. 132.

(16) André Glucksmann, "Nous ne sommes pas tous prolétaires", publicado em Les Temps Modernes, N's. 330 e 331, Paris, janeiro e fevereiro de 1974. Citação da segunda parte, publicada no No 331 de Les Temps Modernes, p. 1361. 
tica, superpõem-se as exigências das relações e estruturas burocráticas, que exigem hierarquia, disciplina e performance.

L'éthique et l'idéologie de la classe dominante puritaine ont modelé l'idéologie de la science en accréditant l'idée que l'homme de science doit être ascétique, insensible et inhumain à la manière de l'entrepreneur capitaliste $\left.{ }^{(17}\right)$.

Nesse contexto é que o princípio da quantidade se impõe como critério universal de fazer e pensar. Num mundo dominado pelas leis de acumulação do capital, ou da reprodução capitalista, o princípio da quantidade necessariamente se impõe também ao trabalho científico. Por trás do ascetismo ou fetichismo metodológico, que se generaliza nas ciências sociais, está a generalização da racionalidade comandada pela produção de mercadoria e lucro, ou mais-valia.

En la medida en que la vida contemporánea está en gran medida estandardizada por efecto de la concentración del poder económico llevada a extremo, en que el individuo es bastant más impotente de lo que se confiesa, los métodos estandardizados y en cierto sentido desindividualizados, son tanto expresión de la situación efectiva como un instrumento adecuado para describirla y entenderla ${ }^{(18)}$.

O resultado desse processo é a fragmentação do objeto das ciências sociais

(17) André Gorz, "Caractères de classe de la science et des travailleurs scientifiques", Les Temps Modernes, $\mathrm{N}^{\circ} 330$, Paris, 1974, pp. 1159-1177, citação das pp. 1166-67.

(18) Theodor W. Adorno y Max Horkheimer, La Sociedad: Leciones de Sociologia, trad. de Floreal Mazía e Irene Cusien, Editorial Proteo, Buenos Aires, 1969, p. 124.
- ou mesmo a destruição desse objeto - e a multiplicação de verdades, leis e conceitos sociológicos, econômicos, políticos, antropológicos e outros sobre um mesmo fato social. A ciência deixa de ser uma forma de conhecimento para tornar-se uma técnica de abordagem de problemas específicos, perfeitamente delimitados, suscetíveis de observação objetiva, mensuração etc. É claro que nesse processo perde-se a noção do todo, do fato social total, ou de relações, processos e estruturas internos e externos. A ênfase do trabalho intelectual tende a concentrar-se sobre os meios de pesquisa e os modos de aperfeiçoar o status quo político-econômico de ocasião; ou as bases políticas, econômicas e culturais do capitalismo.

El método amenaza tanto fetichizar sus asuntos cuanto degenerar él mismo en un fetiche: no en vano predominan en las discusiones de la investigación social empírica - y, en la lógica del procedimiento científico de que hablamos, con todo derecho - las cuestiones de método sobre las de contenido; en lugar de la dignidad de los objetos a investigar entra muchas veces como criterio la objetividad de los hallazgos a hacer con un método; $y$ en los trabajos científicos empíricos, la elección de los objetos de la investigación y el arranque de los estudios se orientan, cuando no por desiderata prático-administrativos, mucho más por los procedimientos disponibles, $y$, si acaso, por los que haya que desarrollar, que por la esencialidad de lo investigado de ahí la índudable intrascendencia de tantos estudios empíricos ${ }^{(19)}$.

(19) Theodor W. Adorno y Max Horkheimer, Sociologia, trad. de Víctor Sanchez de Zavala, Taurus Ediciones, Madrid, 1966, p. 278. Citação do capítulo "La sociologia y la inventigación empírica", de autoria de Adorno. 
Transferem-se para o trabalho intelectual os mesmos critérios pragmáticos que fundamentam a organização e a eficácia da empresa industrial: racionalização, burocratização, divisão social do trabalho, especialização, hierarquia, disciplina, performance, economicidade etc. Science is measurament. As relações e estruturas "racionais" que se impõem ao processo de produção científica acabam por conferir uma segunda natureza à ciência. Ao mesmo tempo, a ciência é transformada numa técnica de poder e numa força produtiva, ela entra direta e amplamente na reprodução das relações e estruturas de dơminação política e apropriação econômica.

A burocratização e a especialização crescentes, no processo de produção científica, provêm do mesmo processo de racionalização generalizada comandado pela reprodução capitalista. A sociedade capitalista é, cada vez mais e em formas renovadas, um sistema de relações e estruturas político-econômicas comandadas pelas exigências da produr:ão de mercadoria e lucro, ou maisvalia. Daí porque a atividade científica se mercantiliza, em todas as suas fases, em seus processos e produtos. E o cientista passa a ser um trabalhador produtivo, na condição de pesquisador, especialista, analista, técnico etc. Algumas vezes ela é duplamente trabalhador produtivo. Em um plano, porque produz uma dissertação ou conhecimento, original ou macaqueado, que se traduz num livro. Neste caso o livro é uma mercadoria como outra qualquer. Mesmo que o tenha escrito por diletantismo, ou para revolucionar ciências e filosofias, nas mãos do editor o trabalho intelectual se transforma em mercadoria, produz lucro.

Cuando Milton, por ejemplo, escribía El Paraíso Perdido, era un obrero improductivo. En cambio, es un obrero productivo el autor que suministra a su editor originales para ser publicados. Milton produjo El Paraíso Perdido como el gusano de seda produce la seda: por un impulso de la naturaleza. Después de lo cual, vendió su producto por 5 libras esterlinas. En cambio, el autor que fabrica libros, manuales de economia política por ejemplo, bajo la dirección de su editor, es un obrero productivo, pues su producción se halla sometida por definición al capital que ha de hacer fructificar ${ }^{(20)}$.

Em outro plano, o cientista é trabalhador produtivo porque o conhecimento (científico ou técnico, prático ou ideológico) que ele produz, aperfeiçoa ou adapta entra direta ou indiretamente no processo de produção, como força produtiva.

Pour le capitalisme, le savoir est rentable, il aide soit à l'exploitation directe, soit à la "circulation", donc à la fois à l'extraction et à la réalisation du profit ${ }^{(21)}$.

A reprodução da sociedade, em suas relações, processos e estruturas políticoeconômicos, envolve a reprodução cultural, em geral, e a científica, em especial. A atividade do cientista é parte importante do processo de produção cultural, processo este que ganha sentido no conjunto da reprodução social.

(20) Karl Marx, Historia Critica de la Teoria de la Plusvalia, 3 vols. trad. de Wenceslao Roces, Fondo de Cultura Economica, México, 1945, vol. I, pp. 285-286.

(21) André Glucksmann, "Nous ne sommes pas tous prolétaires", citado, Les Temps Modernes, $\mathrm{N}^{\circ}$ 331, p. 1360. 